\title{
Studies on the Pathogenesis of Steatorrhea in the Blind Loop Syndrome *
}

\author{
Robert M. Donaldson, JR. $\dagger$ \\ (From the Medical Service, Veterans Administration Hospital, Boston, Mass., and the De- \\ partments of Medicine, Boston University, Boston, Mass., and University of Wisconsin, \\ Madison, $W$ is.)
}

In patients with the blind loop syndrome intestinal abnormalities conducive to stasis and bacterial proliferation within the contents of the small bowel are associated with vitamin $\mathrm{B}_{12}$ deficiency and steatorrhea (1). Mechanisms involved in the pathogenesis of this syndrome have not been defined although evidence derived from patients (2) and experimental animals (3) suggests that the host may be deprived of vitamin $\mathrm{B}_{12}$ because bacterial uptake of microgram quantities of the vitamin makes it unavailable for absorption. A similar explanation for steatorrhea seems less likely, however, since in the case of lipids, bacteria would have to compete for gram rather than microgram quantities. Reports of steatorrhea in clinical $(2,4,5)$ and experimental $(6,7)$ forms of the blind loop syndrome have demonstrated decreased fecal fat excretion after antibiotic therapy, but such studies have not provided evidence concerned with mechanisms whereby small bowel bacterial overgrowth might result in steatorrhea.

Excessive fecal fat losses in the blind loop syndrome could occur in the absence of malabsorption if intestinal production of lipids derived from intestinal bacteria or from sloughed intestinal mucosal cells were increased. On the other hand, it is entirely possible that intraluminal bacteria might be capable of impairing one or more of the processes normally involved in the absorption of dietary fat.

In the present investigation studies were carried out in rats with experimentally induced small

* Submitted for publication May 3, 1965 ; accepted July $16,1965$.

Supported in part by grant AM-08444 from the U. S. Public Health Service.

$\dagger$ Address requests for reprints to Dr. Robert $M$. Donaldson, Dept. of Medicine, University of Wisconsin, Madison, Wis. bowel stasis and in one patient. with the blind loop syndrome. Fat balance studies were performed, and measurements were made of the hydrolysis and fecal excretion of ${ }^{14} \mathrm{C}$-labeled triolein. In addition, the effects of blind loop intestinal juice were observed upon the uptake and esterification of fatty acid by rat intestine in vitro. Finally, an attempt was made to find abnormal bile salts in bacterially contaminated intestinal juice and to demonstrate alteration of labeled cholic acid by bacteria obtained from blind intestinal pouches. The results suggest that steatorrhea in the blind loop syndrome is best explained by poor absorption of dietary fat and that bacterial alteration of bile salts may play a pathogenetic role.

\section{Methods}

Studies in a patient with the blind loop syndrome. A 68-year-old man was studied 7 years after a side-to-side jejunojejunal anastomosis had been performed to relieve small bowel obstruction due to adhesions. Macrocytic, megaloblastic anemia, low serum vitamin $B_{12}$ levels, and steatorrhea were present. Anemia had been corrected by vitamin $B_{12}$ therapy before fat balance studies were begun. Fat balance studies were performed over 6-day periods when the patient ingested approximately $100 \mathrm{~g}$ of fat daily. The estimated amount of fat consumed was periodically checked by assaying a full day's diet for total fatty acids. Feces were kept frozen during the collection period and were homogenized in the container in which they were collected. Total fatty acids present in the diet and in fecal collections were estimated by the method of Van de Kamer, Huinink, and Weyers (8).

Intake and fecal excretion of total fatty acids were measured on several occasions. During control periods the patient received no antibiotic therapy for at least 2 weeks before the fat balance study was begun. On other occasions tetracycline, $1.5 \mathrm{~g}$ daily, was administered orally for 2 weeks before as well as during the fat balance study. On one occasion alteration of the patient's normal intestinal flora was attempted by administration of Lactobacillus casei. This was supplied as a liquid con- 
centrate. ${ }^{1}$ The patient ingested $5 \times 10^{9}$ viable organisms daily for 1 week before and during a fat balance study.

A comparison of two extraction methods for fecal lipids was carried out. Results of analyses for total fecal fatty acids were not significantly different whether hydrolyzed lipids were extracted into petroleum ether as originally described by Van de Kamer and co-workers (8), or into toluene as more recently recommended by Jover and Gordon (9). Fecal fatty acid excretion over a 6-day period was $132.7 \mathrm{~g}$ when determined by petroleum ether extraction, as compared to $131.5 \mathrm{~g}$ by toluene extraction.

On two occasions, once before therapy was begun, and once after the patient had received $1.5 \mathrm{~g}$ of tetracycline daily for 2 weeks, a Miller-Abbott tube was passed under fluoroscopic control into the region of the surgically produced blind loop. In an effort to estimate hydrolysis of radioactive triolein, intestinal juice was collected by siphonage in 30-minute aliquots for 2 hours before and for 2 hours after oral administration of $10 \mu \mathrm{c}$ of triolein${ }^{14} \mathrm{C}$ dissolved in $20 \mathrm{ml}$ of corn oil. Extraction and separation of labeled lipids present in intestinal juice were carried out as described below.

Fat balance studies in rats with experimentally induced small bowel stasis. In female albino rats weighing 200 to $250 \mathrm{~g}$ a small intestinal pouch was surgically created according to the method of Cameron, Watson, and Witts (10). A "self-filling" pouch was made in such a way that peristalsis was in the direction of the blind end of the pouch, allowing stasis of intestinal contents and proliferation of intestinal bacteria. In "self-emptying" pouches, however, peristalsis was in the opposite direction and tended to keep the sac empty. A self-filling pouch $8 \mathrm{~cm}$ in length was formed either proximally (10 $\mathrm{cm}$ distal to the ligament of Treitz) in the mid-small bowel, or distally (at the ileocecal valve). Self-emptying pouches were made in the mid-small bowel only.

Operated and unoperated rats were maintained in individual cages and were fed a fiber-free, vitamin-enriched diet containing 6.0 to $8.5 \mathrm{~g}$ of lipid per $100 \mathrm{~g}$ of food. ${ }^{2}$ The amount of food ingested was estimated by differential weighing of food cups. With the aid of a feces-urine separator, stools were collected twice daily and stored at $-20^{\circ} \mathrm{C}$. At the end of each 6-day period the entire fecal collection from each rat, as well as a sample of the diet, was analyzed for total fatty acids (8). In one series of analyses portions of fecal digests were also extracted into toluene, according to the method of Jover and Gordon (9). In three control rats and in ten rats with blind pouches fecal fat excretion was not different when measured by these two extraction procedures. Fecal fat excretion was expressed as per cent of dietary fat intake.

Fecal excretion of radioactivity by rats fed ${ }^{14} \mathrm{C}$-labeled lipids. Fecal excretion of radioactivity by rats was measured after oral administration of either triolein-carboxyl-

1 Hood Milk Co., Boston, Mass.

2 Vitamin B-complex diet, Nutritional Biochemicals, Cleveland, Ohio.
${ }^{14} \mathrm{C}$ (SA $5.4 \mathrm{mc}$ per mmole) ${ }^{3}$ or oleic acid-1- ${ }^{14} \mathrm{C}$ (SA 2.1 mc per mmole) 4 diluted with corn oil. Both radioactive compounds were found to be homogeneous when chromatographed on thin layer silicic acid. From a tuberculin syringe $1 \mathrm{ml}$ of corn oil containing $0.06 \mu \mathrm{c}$ of labeled lipid was injected through fine polyethylene tubes placed in the stomachs of unanesthetized rats, and with a separate syringe the polyethylene tubes were flushed with 1 $\mathrm{ml}$ of water. The tuberculin syringe was weighed before and after the dose of radioactivity was given, and weighed aliquots of the administered material were used as standards.

These standards as well as the total 6-day fecal collection from each rat were digested and extracted into petroleum ether as described by Van de Kamer and associates (8). Each of four aliquots (usually $5 \mathrm{ml}$ ) of the petroleum ether extract was then evaporated in a counting tube. To two counting tubes was added $13 \mathrm{ml}$ of a toluene-based scintillant ${ }^{5}$ as well as $2 \mathrm{ml}$ of scintillant containing ${ }^{14} \mathrm{C}$-labeled toluene that served as an internal quenching standard. To the other two counting tubes $15 \mathrm{ml}$ of scintillant was added. Radioactivity in the samples was assayed by means of a Packard Tricarb liquid: scintillation counter. In 12 experiments, recovery of $94 \% \pm 4.1 \mathrm{SD}$ of 0.002 to $0.06 \mu \mathrm{C}$ of ${ }^{14} \mathrm{C}$-labeled triolein added to rat feces was demonstrated with this technique.

Hydrolysis of ${ }^{14} \mathrm{C}$-labeled triolein. Triolein-carboxyl- $-{ }^{14} \mathrm{C}$, $1 \mu \mathrm{c}$ dissolved in $1 \mathrm{ml}$ of corn oil, was injected directly into the surgically exposed duodenums of rats lightly anesthetized with ether. After 30 minutes the contents of the entire small bowel were flushed out with $0.9 \%$ $\mathrm{NaCl}$ and centrifuged at $15,000 \times g$ for 20 minutes. The sediment was washed three times with saline. Lipids were extracted from the sediment and from the supernatant by the Folch procedure (11), and were fractionated by thin layer chromatography on silicic acid. Petroleum ether, diethyl ether, and glacial acetic acid (90:20:1.5) constituted the solvent system used. The per cent of recovered radioactivity bound to the bacteria-containing sediment was calculated for each experiment.

Uptake and esterification of ${ }^{14} C$-labeled oleic acid by slices of rat intestine. Intestinal juice was collected from previously unoperated rats and from rats with steatorrhea and mid-intestinal self-filling pouches after they had been sacrificed by a blow on the head. The entire small intestine was flushed with $50 \mathrm{ml}$ of distilled water, and the contents obtained were centrifuged at $15,000 \times g$ for 20 minutes. The supernatant was lyophilized and stored at $-20^{\circ} \mathrm{C}$ until ready for use at which time the lyophilized material was redissolved in $2 \mathrm{ml}$ of Krebs-Ringer bicarbonate solution (KRB) that contained $0.25 \%$ glucose and was adjusted to $\mathrm{pH}$ 7.4. This preparation of intestinal juice was used in experiments measuring in vitro uptake and esterification of labeled oleic acid.

\footnotetext{
3 Tracerlab, Waltham, Mass.

4 New England Nuclear Corp., Boston, Mass.

${ }^{5}$ Liquiflour, Pilot Chemical Co., Waltham, Mass.
} 
Esterification of fatty acids by slices of rat intestine in vitro was measured by modifications of the procedure described by Dawson and Isselbacher (12). Everted rat intestinal slices were prepared and distributed into incubation flasks as described (12). Control incubation flasks contained $4 \mathrm{ml}$ of $\mathrm{KRB}$, whereas experimental flasks contained $2 \mathrm{ml}$ of $\mathrm{KRB}$ and $2 \mathrm{ml}$ of redissolved intestinal juice. After intestinal slices had been incubated for 15 minutes in a Dubnoff metabolic shaker at $25^{\circ} \mathrm{C}$ in an atmosphere of $95 \% \mathrm{O}_{2}, 0.10 \mu$ mole of ${ }^{14} \mathrm{C}$-labeled oleic acid in $10 \%$ human serum albumin was added to each flask, and incubation was continued for an additional 30 minutes. The intestinal segments were then washed in three changes of chilled $0.9 \% \mathrm{NaCl}$, blotted dry, weighed, and homogenized in chloroform-methanol by means of Potter-Elvehjem glass tissue grinders. Tissue lipids were extracted by the method of Folch, Lees, and Sloane Stanley (11).

To determine total radioactivity taken up by intestinal slices, 5-ml aliquots of tissue extract were transferred to counting vials, evaporated to dryness, and prepared for liquid scintillation counting as described above. The remainder of the extract was evaporated to dryness at $50^{\circ} \mathrm{C}$ under nitrogen and redissolved in $0.1 \mathrm{ml}$ of chloroform. Samples were then subjected to silicic acid thin layer chromatography in duplicate with petroleum ether: diethyl ether: glacial acetic acid $(90: 20: 1.5)$ used as the solvent system. A mixture of purified triglyceride, diglyceride, monoglyceride, and free fatty acids ${ }^{6}$ served as standard. Areas of silicic acid containing appropriate lipid fractions were located by iodine vapor and were scraped from the plate directly into counting vials that contained toluene-based scintillant. In 155 separations of radioactivity present in tissue extracts $92 \% \pm 11.0 \mathrm{SD}$ of the radioactivity applied to chromatographic plates was recovered from the scrapings.

Measurement of bile salts. Cholic and deoxycholic acid ${ }^{7}$ were recrystallized three times from $70 \%$ ethanol. Bile salts were extracted from intestinal juice and from incubation mixtures by the method described by Borgström, Lundh, and Hofmann (13), and free deoxycholate concentrations were estimated by the method of Sjövall (14). Free cholate and deoxycholate were separated by thin layer silicic acid chromatography with solvent systems described by Eneroth (15) and by Hofmann (16). Location on the chromatograms was accomplished with iodine vapor. ${ }^{14} \mathrm{C}$-labeled cholic and deoxycholic acid 4 were also subjected to thin-layer chromatography. Appropriate areas of silicic acid were scraped from the plates and eluted with $70 \%$ ethanol. The eluate was evaporated to dryness in counting flasks and prepared for scintillation counting by addition of a dioxane-based scintillant.

Statistical significance of results was ascertained by application of Fisher's $t$ test or by calculating correlation coefficients (17).

${ }^{6}$ Kindly supplied by Dr. F. H. Mattson, Procter and Gamble, Cincinnati, Ohio.

‘ Calbiochem, Los Angeles, Calif.

\section{Results}

Studies in the patient with the blind loop syndrome. Steatorrhea was corrected on four separate occasions by the administration of tetracycline (Table I). Since tetracycline might reduce fecal fat excretion as a result of its action on intestinal bacteria or possibly by some other mechanism, an attempt was made to alter the bacterial populations of the patient's intestine by some means other than an antibiotic. Feeding of large quantities of $L$. case $i$ failed to eliminate steatorrhea. Although L. casei was cultured from the stool, the experiment was inconclusive because bacterial cultures of feces also demonstrated persistence of usual coliform organisms. Thus the usual flora had not been replaced by $L$. casei.

When the patient was not receiving tetracycline, intestinal contents recovered from the region of the blind loop were turbid, had a fecal odor, and contained $5 \times 10^{7}$ Escherichia coli per ml. After 2 weeks of tetracycline therapy jejunal contents had a normal appearance and contained less than $1,000 \mathrm{E}$. coli per $\mathrm{ml}$. Both before and after antibiotic therapy ${ }^{14} \mathrm{C}$-labeled triolein was given orally, and radioactive lipids were extracted from the intestinal contents. On both occasions more than $90 \%$ of the radioactivity recovered was in the form of fatty acid and monoglyceride, indicating essentially normal lipolysis even when the patient was having steatorrhea. Only $0.2 \%$ of recovered radioactivity was bound to bacteriacontaining sediment of the intestinal contents at a time when marked bacterial overgrowth was obvious.

Fat balance studies in rats with experimentally induced bacterial stasis. Rats with self-filling

TABLE I

Fat balance study in a patient with the blind loop syndrome

\begin{tabular}{|c|c|c|}
\hline Dates & Treatment & $\begin{array}{l}\text { Fecal fat } \\
\text { excretion }\end{array}$ \\
\hline $\begin{array}{l}1 / 2 / 63 \text { to } 1 / 8 / 63 \\
1 / 22 / 63 \text { to } 1 / 28 / 63 \\
2 / 15 / 63 \text { to } 2 / 21 / 63 \\
3 / 7 / 63 \text { to } 3 / 13 / 63 \\
3 / 29 / 63 \text { to } 4 / 4 / 63 \\
4 / 19 / 63 \text { to } 4 / 25 / 63 \\
5 / 18 / 63 \text { to } 5 / 24 / 63 \\
6 / 8 / 63 \text { to } 6 / 14 / 63\end{array}$ & $\begin{array}{l}\text { Control } \\
\text { Tetracycline } \\
\text { Control } \\
\text { Tetracycline } \\
\text { Control } \\
\text { Tetracycline } \\
\text { Lactobacilli } \\
\text { Tetracycline }\end{array}$ & $\begin{array}{c}\text { \% of intake } \\
33.7 \\
7.0 \\
20.4 \\
3.4 \\
24.0 \\
4.4 \\
29.1 \\
5.1\end{array}$ \\
\hline
\end{tabular}




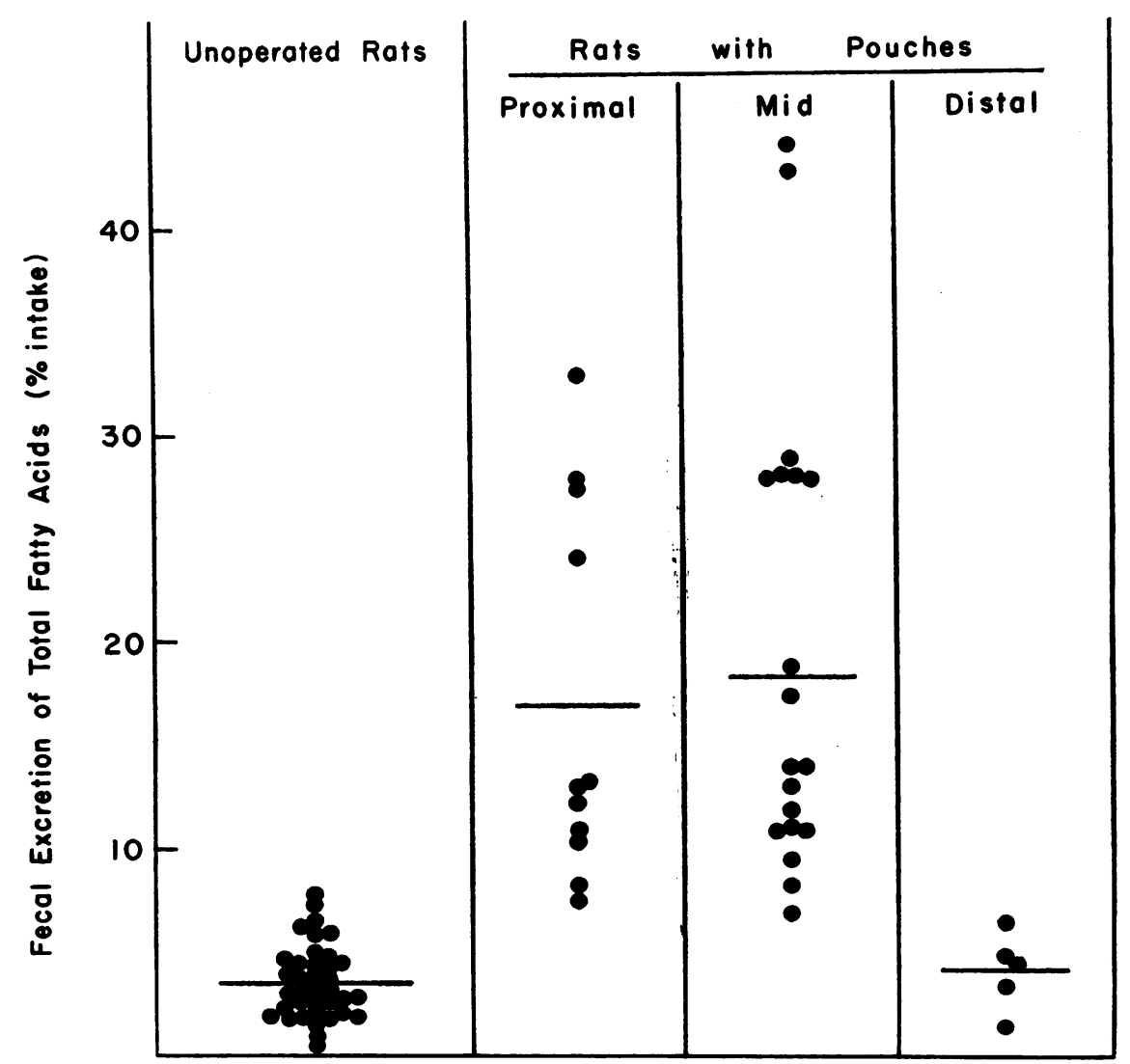

Fig. 1. Fecal fat excretion in rats with intestinal pouches. Proximal pouches were formed $10 \mathrm{~cm}$ distal to the ligament of Treitz, mid-intestinal pouches were $40 \mathrm{~cm}$ from the ligament of Treitz, and distal pouches were made at the ileocecal valve. All pouches were of the "self-filling" type. Each dot represents the average result for two to five balance studies performed in an individual rat. The horizontal lines indicate average values for each group.

pouches formed in the proximal or mid-small intestine excreted significantly increased $(\mathrm{p}<$ $0.001)$ quantities of fat in the feces compared to unoperated rats, whereas animals with self-filling pouches made at the ileocecal valve did not have steatorrhea (Figure 1). Balance studies were performed two to five times on each rat. Results of balance studies performed in an individual rat were always less than $\pm 15 \%$ of the mean value for that animal. Fecal fat excretion in six rats with self-emptying pouches was not different from that observed in unoperated animals. Fat balance studies were performed in 10 rats before and at weekly intervals after formation of midintestinal self-filling sacs (Table II). Fecal fat excretion gradually increased during the first month after operation and was promptly reduced by the administration of neomycin and by surgical removal of the pouch.

Fecal excretion of radioactivity by rats fed ${ }^{14} \mathrm{C}$ labeled lipids. After oral administration of either triolein-carboxylic- ${ }^{14} \mathrm{C}$ or oleic acid- $1-{ }^{14} \mathrm{C}$ the percentage of administered radioactivity recovered in petroleum ether extracts of fecal digests was significantly greater $(p<0.001)$ in rats with selffilling diverticula than in unoperated animals (Figure 2). In each animal two to four fecal excretion tests were carried out. Results obtained in an individual animal were always less than $\pm 10 \%$ of the mean value for that animal. In 95 individual experiments carried out in 20 rats with pouches, total fecal fat excretion expressed as per cent of intake was plotted against percentage of radioactivity recovered in the stools 
TABLE II

Weekly fat balance studies in 10 rats after formation of mid-intestinal pouches

\begin{tabular}{|c|c|}
\hline $\begin{array}{l}\text { Weeks after } \\
\text { operation }\end{array}$ & Fecal fat excretion \\
\hline & $\begin{array}{l}\text { average \% of } \\
\text { intake } \pm S D\end{array}$ \\
\hline 0 & $3.9 \pm 0.4$ \\
\hline 1 & $6.9 \pm 3.4$ \\
\hline 2 & $8.8 \pm 3.6$ \\
\hline 3 & $13.8 \pm 4.2$ \\
\hline 4 & $17.0 \pm 4.7$ \\
\hline $5^{*}$ & $9.1 \pm 5.2^{*}$ \\
\hline 6 & $18.2 \pm 5.6$ \\
\hline 7 & $17.9 \pm 4.3$ \\
\hline 8 & $15.0 \pm 3.8$ \\
\hline 9 & $19.8 \pm 4.1$ \\
\hline $11 \dagger$ & $5.6 \pm 1.3 \dagger$ \\
\hline $12 \dagger$ & $4.5 \pm 1.0 \dagger$ \\
\hline
\end{tabular}

* Neomycin, $50 \mathrm{mg}$ daily, was given for 5 days by mixing the antibiotic with the diet.

$\dagger$ Pouches were surgically removed during the tenth week. Only seven rats were studied during weeks 11 and 12.

after the feeding of either labeled triolein or labeled oleic acid (Figure 3 ). A significant correlation $(r=0.84)$ was observed between the

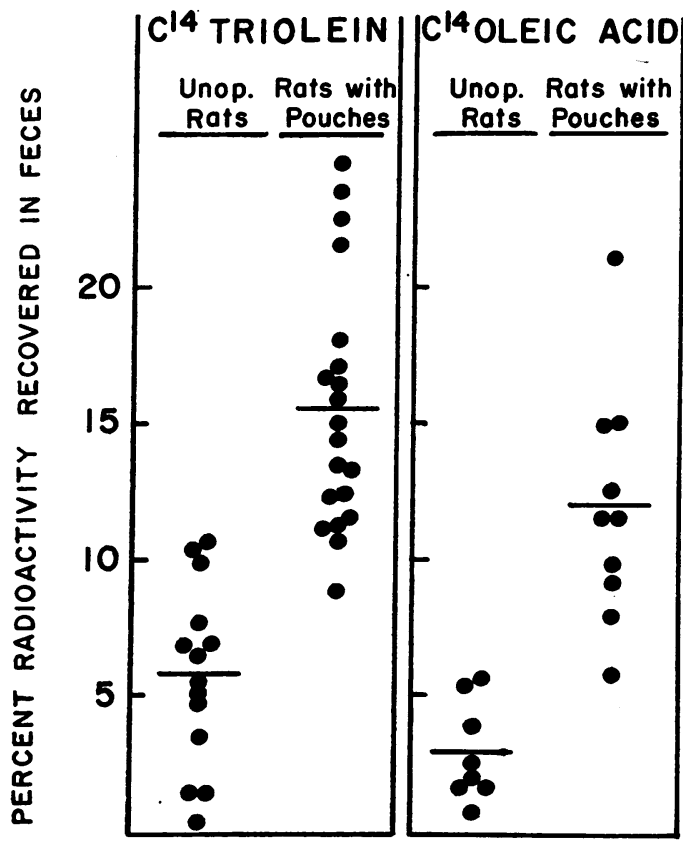

FIG. 2. FECAL EXCRETION OF LIPID EXTRACTABLE RADIOACTIVITY AFTER ORAL ADMINISTRATION OF TRIOLEINCARBOXYL- ${ }^{14} \mathrm{C}$ AND OLEIC ACID-1 $-{ }^{14} \mathrm{C}$ TO RATS WITH INTESTINAL POUCHÉs. Each dot represents. the average result for two to four studies performed in an individual rat. The horizontal lines indicate mean values for each group. The results for rats with pouches are compared with those for unoperated rats.

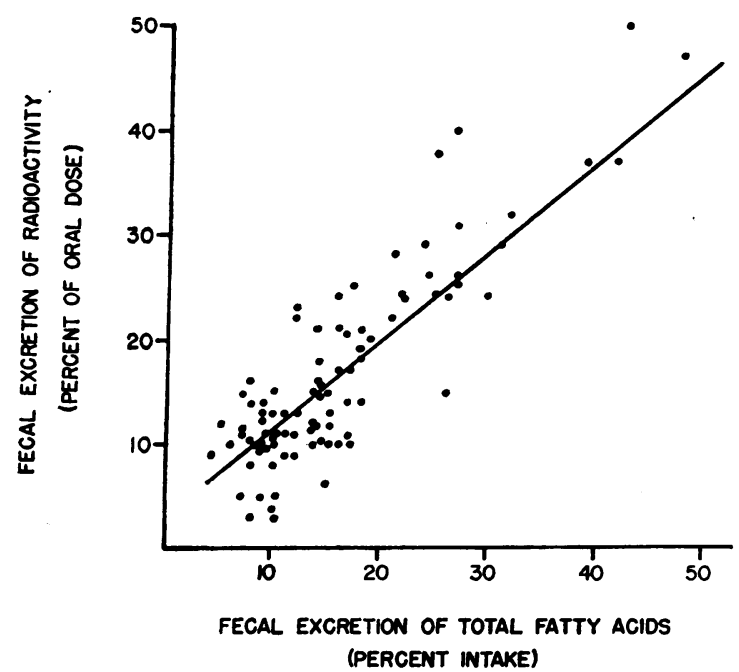

Fig. 3. Correlation between fecal fat excretion AND FECAL EXCRETION OF LIPID EXTRACTABLE RADIOACTIVITY AFTER ORAL ADMINISTRATION OF ${ }^{14} \mathrm{C}$-LABELED TRIOLEIN OR OLEIC ACID. Dots represent 95 individual studies performed in 20 rats, and the least squares regression line is also shown.

fecal excretion of radioactivity after the oral administration of labeled fats and total fecal fat excretion as determined by fat balance studies.

Hydrolysis of ${ }^{14} \mathrm{C}$-labeled triolein. Within 30 minutes after labeled triolein was injected directly into the duodenum most of the radioactivity recovered from small intestinal contents was found to be in the form of fatty acid and monoglyceride. As can be seen in Table III, intraluminal hydrolysis of labeled triolein was equally efficient in rats with self-filling pouches and steatorrhea and in unoperated control animals.

In all experiments in which intestinal juice was obtained after administration of labeled triolein to rats with blind pouches, less than $0.6 \%$ of

TABLE III

Intestinal hydrolysis of ${ }^{14}$ C-labeled triolein

\begin{tabular}{|c|c|c|}
\hline $\begin{array}{l}\text { Radioactivity re- } \\
\text { covered from in- } \\
\text { testinal contents as: }\end{array}$ & $\begin{array}{l}9 \text { unoperated } \\
\text { rats }\end{array}$ & $\begin{array}{l}6 \text { rats with } \\
\text { pouches }\end{array}$ \\
\hline & \multicolumn{2}{|c|}{$\begin{array}{l}\% \text { of total radioactivity } \\
\text { recovered } \pm S D\end{array}$} \\
\hline $\begin{array}{l}\text { Unhydrolyzed } \\
\text { triglyceride } \\
\text { Diglyceride } \\
\text { Monoglyceride } \\
\text { Fatty acid }\end{array}$ & $\begin{array}{r}4 \pm 2 \\
8 \pm 5 \\
23 \pm 13 \\
65 \pm 18\end{array}$ & $\begin{array}{r}8 \pm 6 \\
5 \pm 1 \\
20 \pm 9 \\
67 \pm 8\end{array}$ \\
\hline
\end{tabular}


TABLE IV

In vitro uptake and esterification of oleic acid-1 $1{ }^{14} \mathrm{C}$ by rat intestine

\begin{tabular}{|c|c|c|c|c|c|c|}
\hline \multirow[b]{2}{*}{ Additions } & \multirow{2}{*}{$\begin{array}{l}\text { No. of } \\
\text { experi- } \\
\text { ments** }\end{array}$} & \multirow[b]{2}{*}{ Total uptake } & \multicolumn{4}{|c|}{ Radioactivity recovered from tissue as: } \\
\hline & & & Triglyceride & Diglyceride & $\begin{array}{c}\text { Monogly- } \\
\text { ceridet }\end{array}$ & Fatty acid \\
\hline & & $\underset{\text { intestine } \pm S D}{\text { mumoles } / g}$ & \multicolumn{4}{|c|}{$\%$ radioactivity $\pm S D$} \\
\hline None & 16 & $12.8 \pm 1.7$ & $62 \pm 5.1$ & $8 \pm 3.0$ & $17 \pm 4.1$ & $13 \pm 4.8$ \\
\hline Cold & 6 & $2.6 \pm 1.2$ & $39 \pm 6.8$ & $6 \pm 4.1$ & $16 \pm 8.0$ & $39 \pm 4.3$ \\
\hline $\mathrm{NaCN}$ & 6 & $7.8 \pm 0.8$ & $48 \pm 7.1$ & $4 \pm 3.0$ & $11 \pm 2.0$ & $37 \pm 5.2$ \\
\hline $\begin{array}{l}\text { Intestinal juice from: } \\
\text { Unoperated rats } \\
\text { Rats with pouches } \\
\text { Untreated patient } \\
\text { Treated patient }\end{array}$ & $\begin{array}{r}6 \\
10 \\
1 \\
1\end{array}$ & $\begin{array}{r}15.6 \pm 2.0 \\
8.2 \pm 2.8 \\
7.5 \\
12.2\end{array}$ & $\begin{array}{l}69 \pm 3.6 \\
49 \pm 6.0 \\
13 \\
52\end{array}$ & $\begin{array}{l}4 \pm 1.9 \\
7 \pm 2.6 \\
9 \\
7\end{array}$ & $\begin{array}{l}17 \pm 2.8 \\
13 \pm 4.6 \\
13 \\
12\end{array}$ & $\begin{array}{l}10 \pm 2.9 \\
31 \pm 5.3 \\
65 \\
25\end{array}$ \\
\hline $\begin{array}{l}\text { Blind loop intestinal juice heated } \\
\text { at } 100^{\circ} \mathrm{C} \text { for } 60 \text { minutes } \\
\text { Ethanol extract }\end{array}$ & $\begin{array}{l}4 \\
6\end{array}$ & $\begin{array}{l}7.6 \pm 3.1 \\
9.1 \pm 2.4\end{array}$ & $\begin{array}{l}37 \pm 4.3 \\
50 \pm 6.8\end{array}$ & $\begin{array}{l}6 \pm 2.8 \\
5 \pm 1.7\end{array}$ & $\begin{array}{l}14 \pm 3.1 \\
16 \pm 4.0\end{array}$ & $\begin{array}{l}43 \pm 4.9 \\
29 \pm 3.7\end{array}$ \\
\hline
\end{tabular}

* Each experiment was performed in duplicate flasks, and duplicate results never varied more than $10 \%$. Control and experimental flasks were always incubated simultaneously.

$\dagger$ No effort was made to separate phospholipids from monoglycerides.

recovered radioactivity was bound to bacteriacontaining sediment of the intestinal contents.

In vitro uptake and esterification of oleic acid$1{ }^{14} C$ by rat intestine. As shown in Table IV labeled oleic acid was observed to be taken up from the incubation medium and esterified by slices of rat intestine. The major proportion of

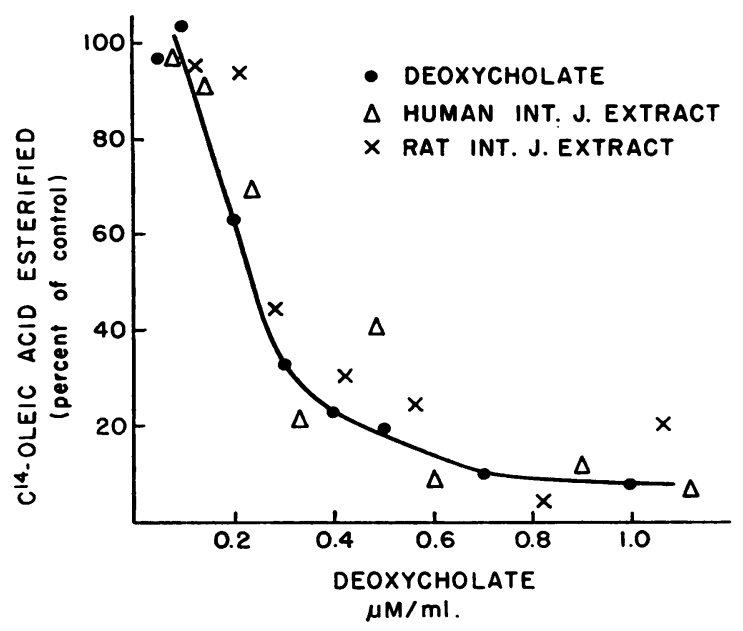

Fig. 4. EFfect of deoxycholate and ethanol ExTRACTS OF BLIND LOOP INTESTINAL JUICE ON ESTERIFICATION OF OLEIC ACID-1-14 C BY RAT INTESTINAL SLICES. Inhibition of esterification is compared with measured deoxycholate concentrations in extracts of bacterially contaminated intestinal juice obtained from the patient (triangles) and from rats (crosses). The circles indicate inhibition observed with authentic deoxycholate at various concentrations. the radioactivity recovered from the tissue was in the form of triglyceride. When $\mathrm{NaCN}$ was added to the incubation medium or when flasks were incubated at $4^{\circ} \mathrm{C}$ both tissue uptake of oleic acid and its esterification to triglyceride were significantly $(p<0.001)$ reduced. Addition of intestinal juice obtained from six unoperated rats produced a slight but consistent increase in uptake of oleic acid-1-14 $\mathrm{C}$. On the other hand, both uptake and esterification were inhibited by juice obtained from 10 rats with intestinal pouches and steatorrhea. Intestinal juice from the patient was inhibitory when obtained before, but not after, treatment with tetracycline. The inhibitory effect was not destroyed when intestinal juice was boiled or when it was extracted with 4 vol of ethanol, evaporated to dryness, and redissolved in KRB.

Measurement of bile salts. The supernatant fluid obtained from $50 \mathrm{ml}$ of intestinal contents that was collected from the untreated patient was extracted with 4 vol of ethanol, evaporated to dryness, and redissolved in $5 \mathrm{ml}$ of $\mathrm{KRB}$. The pooled supernatant of intestinal contents obtained from 10 rats with intestinal diverticula was treated similarly. Serial dilutions of this concentrated rat and human intestinal juice were added to incubation flasks, and the effect on esterification of labeled oleic acid was determined. At the end of the incubation the medium was 
extracted for free bile salts (13), and its deoxycholate concentration was estimated. For comparison uptake and esterification of oleic acid-1${ }^{14} \mathrm{C}$ were also measured when authentic free deoxycholate was added to incubation flasks. The results are summarized in Figure 4. Dilution of both rat and human intestinal juice extracts resulted in diminution of their inhibitory effect, and the extent of inhibition was in general proportional to the measured concentration of deoxycholate-like material in the incubation flask. Furthermore, the inhibitory effects of authentic free deoxycholate were quantitatively similar to those observed with intestinal juice extracts containing comparable quantities of measured deoxycholate.

Sediment of rat intestinal pouch contents containing a mixed bacterial flora was incubated at $37^{\circ} \mathrm{C}$ for 3 hours in thioglycollate broth containing $1 \mu$ mole per $\mathrm{ml}$ of ${ }^{14} \mathrm{C}$-labeled cholic acid.

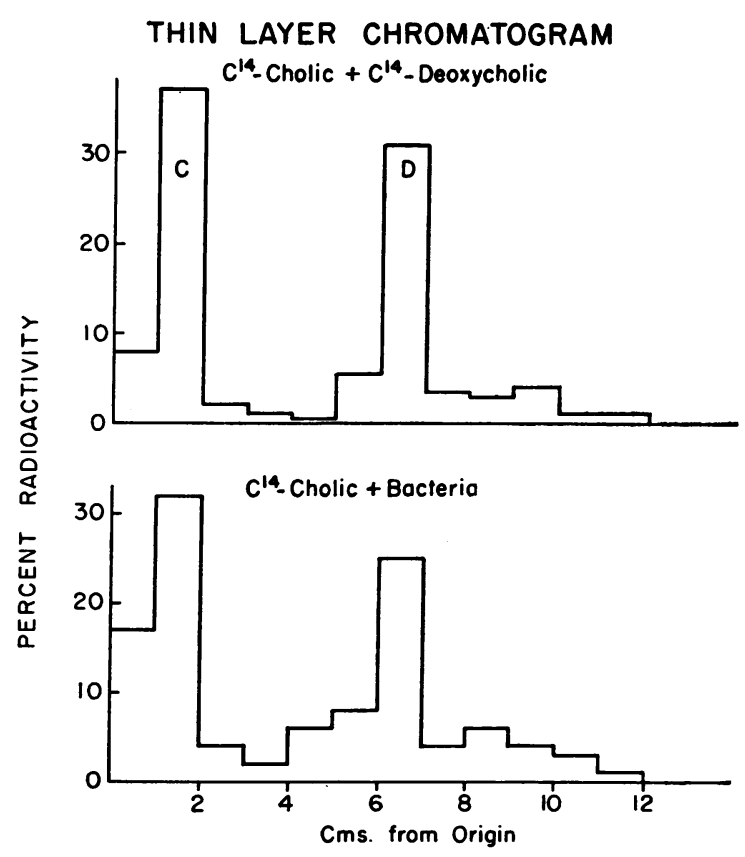

Fig. 5. EFFect of BLINd POUCH BACTERIA ON ${ }^{14} \mathrm{C}$-LABELED CHOLIC ACID. Adsorption chromatography was performed on thin layer silicic acid with a solvent system consisting of trimethylpentane, ethyl acetate, and acetic acid $(10: 10: 2)$. The upper section shows separation of labeled cholic acid (C) and deoxycholic acid (D). The lower section shows distribution of radioactivity (average results of three experiments) when ${ }^{14} \mathrm{C}$-labeled cholic acid was incubated with bacteria-rich sediment obtained from rat intestinal pouches.

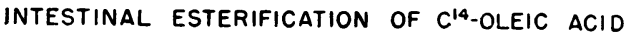

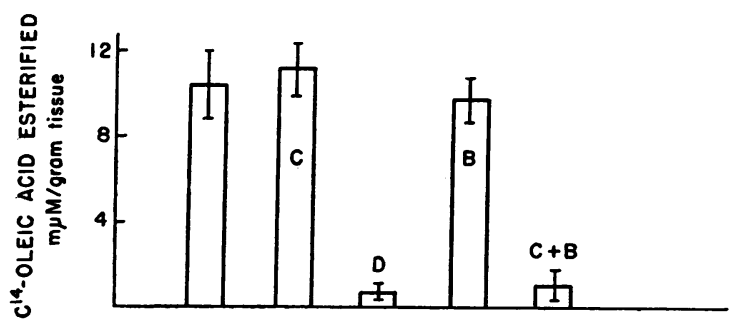

Fig. 6. Effect of incubation of cholic acid with BLIND POUCH BACTERIA ON IN VITRO ESTERIFICATION OF FATTY ACID BY RAT INTESTINE. The bars indicate average results of five experiments. The short lines represent standard deviation. Unlabeled bar $=$ Krebs-Ringer bicarbonate (KRB) alone. $\mathrm{C}=\mathrm{KRB}$ containing cholate, 1 mole per $\mathrm{ml}$. $\mathrm{D}=\mathrm{KRB}$ containing deoxycholate, $1 \mu$ mole per ml. $B=$ supernatant fluid obtained after bacteria-rich sediment was incubated in thioglycollate broth for 3 hours at $37^{\circ} \mathrm{C}$. $\mathrm{C}+\mathrm{B}=$ supernatant fluid obtained after sediment was incubated in thioglycollate broth containing cholate, $1 \mu$ mole per $\mathrm{ml}$.

Chromatography on thin layer silicic acid demonstrated production of a ${ }^{14} \mathrm{C}$-labeled compound having chromatographic characteristics similar to those of deoxycholate (Figure 5). When pure cultures of E. coli, Pseudomonas aeruginosa, Proteus vulgaris, or Streptococcus fecalis obtained from blind pouches were mixed with labeled cholic acid, bacterial conversion could not be demonstrated.

As shown in Figure 6, free cholic acid in a concentration of $1.0 \mu$ mole per $\mathrm{ml}$ did not inhibit in vitro intestinal esterification of labeled oleic acids, whereas the same concentration of deoxycholic acid was markedly inhibitory. The supernatant of a mixed intestinal bacterial culture did not alter in vitro esterification. When cholic acid was added to the bacterial culture, however, the resulting supernatant fluid was inhibitory.

Histological studies. A suction biopsy taken from the jejunum of the patient at a time when the small bowel lumen was massively contaminated with bacteria appeared to be histologically normal. Examination of the jejunal mucosa of six rats with blind pouches and steatorrhea failed to demonstrate any striking abnormality by light microscopy when compared with the mucosa of unoperated animals. Everted intestinal rings incubated in KRB for 45 minutes had the same morphological appearance as everted slices that 
were fixed immediately after the animal was sacrificed. Intestinal slices incubated in media containing measured or authentic deoxycholate in a concentration of $0.6 \mu$ mole per $\mathrm{ml}$ or greater showed the marked destruction of mucosa previously noted by Dawson and Isselbacher (12). No such effect was observed, however, with deoxycholate concentrations of less than $0.5 \mu$ mole per ml.

\section{Discussion}

Administration of tetracycline to the patient with the blind loop syndrome corrected steatorrhea and at the same time reduced the numbers of bacteria present in the small bowel. Similarly, administration of neomycin or surgical extirpation of the blind pouch resulted in prompt reduction in fecal fat excretion in rats with small bowel diverticula. Thus, steatorrhea both in the patient and in the experimental animals can reasonably be attributed to bacterial proliferation within the lumen of the small intestine.

When ${ }^{14} \mathrm{C}$-labeled fats were administered to rats with blind pouches, the amount of radioactivity recovered from the lipid fraction of feces was increased. Furthermore, the proportion of orally administered radioactivity excreted in the stool by these animals correlated closely with the per cent of total fat intake that was excreted in the feces. Since the fecal excretion of orally administered labeled lipid was not consistently less than the proportion of total ingested lipid that appeared in the stool, no evidence was obtained to support the concept that increased intestinal production or secretion of lipid constituted an important source of the steatorrhea observed in the experimental blind loop syndrome. On the other hand, these data would not distinguish between impaired absorption and increased loss of endogenous fats if the labeled triolein or oleic acid mixed immediately with the intraluminal lipid pool throughout the small bowel before significant quantities of radioactivity could be absorbed. If this occurred, then fecal loss of radioactivity would simply be proportional to the total intestinal lipid pool whether that pool were due to decreased absorption of dietary fat or increased intestinal production or secretion of fat. Absorption of dietary fat, however, occurs mainly in the proximal small bowel, whereas synthesis or secretion of lipid would be expected along the length of the intestine. Furthermore the rapidity with which lipids are absorbed would suggest that significant absorption of the labeled fats would occur before mixing with lipids along the length of the intestine would be complete. From the observed correlation between fecal excretion of radioactivity and total fecal fat excretion it seems likely that the steatorrhea observed in the experimental blind loop syndrome is best explained on the basis of malabsorption of dietary fat.

Webb, James, and Kellock (18) have demonstrated the presence of hydroxylated fatty acids in the feces of certain patients with steatorrhea. These hydroxylated fatty acids result from bacterial metabolism (19) and, according to Jover and Gordon (9), are extracted into toluene but not into petroleum ether. Although intestinal bacterial formation of significant quantities of hydroxy acids might reasonably be expected to contribute significantly to the steatorrhea observed in the blind loop syndrome, fecal fatty acid excretion determined by toluene extraction was not different from that measured by petroleum ether extraction of the feces of the patient and experimental animals with the blind loop syndrome. The results therefore do not support an important role for bacterial production of hydroxylated fatty acids in the pathogenesis of blind loop steatorrhea.

Bacterial overgrowth in the lumen of the small bowel might possibly cause fat malabsorption as a result of direct damage to the intestinal epithelium. Although blunting of jejunal villi has been described in one case of jejunal diverticulosis (20), in most instances of either clinical (4, $5)$ or experimental $(7,21)$ malabsorption associated with excessive bacterial proliferation in the small intestine, the intestinal mucosa has been reported to be essentially normal by light microscopy. In this study no striking histological abnormality was encountered.

Intraluminal destruction of lipase by bacteria is also a conceivable mechanism for fat malabsorption in the blind loop syndrome. In rats with blind pouches, however, labeled fatty acid and triglyceride were both poorly absorbed, and intestinal lipolysis was observed to be as efficient 
in rats with steatorrhea as in control animals. In addition, the patient with the blind loop syndrome demonstrated nearly complete intestinal hydrolysis of triglyceride in the presence of massive bacterial contamination of the jejunum and definite steatorrhea. From these results bacterial destruction of lipase would appear to be an unlikely explanation for steatorrhea. It remains possible, of course, that bacteria themselves may have a lipolytic effect.

It has previously been shown that when radioactive cyanocobalamin was administered orally to rats with blind pouches, most of the radioactivity recovered from intestinal contents was bound to bacteria (3). In the present study, however, when labeled triglyceride or fatty acid was administered to the patient or to experimental animals, less than $1 \%$ of the radioactivity recovered from intestinal contents was present in the centrifuged sediment. Bacterial uptake of ingested fat would therefore seem to be an unlikely mechanism for fat malabsorption in the blind loop syndrome.

The role of bile salts in normal fat absorption has been the subject of much recent attention. As a result of the formation of mixed micelles with monoglyceride and free fatty acids, bile salts play an important role in the dispersion of lipids in the aqueous intestinal contents (22). In addition, in vitro (12) and in vivo (23) studies suggest that conjugated bile salts may be necessary for normal intestinal esterification of fatty acids, an important step in fat absorption. As previously suggested by Dawson and Isselbacher (12), it is possible that bile salt metabolism might be altered in the blind loop syndrome since intestinal microorganisms are capable of hydrolyzing conjugated bile salts (24) and of converting cholate to deoxycholate (25) and other bile salt derivatives (26). Bacterial formation of free deoxycholate or a closely related compound might be of particular importance since deoxycholate inhibits intestinal esterification of fatty acids in vitro (11).

In an attempt to extend the observations of Dawson and Isselbacher (12) uptake and esterification of fatty acid by rat intestine were measured in vitro (Table IV). These workers noted that the principal effect of various inhibitors was on esterification rather than on uptake of the fatty acid. In the present study, however, incubation in the cold or in the presence of inhibitory substances resulted in greater impairment of fatty acid uptake than of esterification. The experimental technique differed somewhat from that described by Dawson and Isselbacher in that labeled oleic rather than palmitic acid was used, intestinal slices were preincubated with inhibitors before addition of labeled fatty acid, and a higher concentration of albumin was present in the incubation medium. Nevertheless the differences in the relative effects of inhibitors upon uptake and esterification remain unexplained.

In any event the supernatant of bacterially contaminated intestinal juice inhibited both uptake and esterification of labeled oleic acid by rat intestine in vitro. That such inhibition might result from bacterial action of bile salts was suggested by several observations. The inhibitory factor was not destroyed by boiling or by extraction into alcohol, and the extent of inhibition was proportional to the measured concentration of deoxycholate-like material in the incubation medium. When mixed intestinal bacteria obtained from blind pouches of rats were incubated with cholic acid the resulting solution was found to be inhibitory. Furthermore, incubation of bacteria from blind pouches with labeled cholic acid yielded a radioactive substance chromatographically similar to deoxycholic acid. Conversion of cholic to deoxycholic acid by mixed rat cecal bacteria has been described previously (25), but formation of deoxycholate by pure cultures of intestinal bacteria has been difficult to demonstrate (26) and was not accomplished in the present study.

Bacterial alteration of bile salts might also result in diminished fat absorption because of subsequent impaired formation of mixed micelles. Kim and co-workers (27) have recently presented preliminary data that suggest that the proportion of ingested lipid recovered from the micellar phase of intestinal contents was reduced in a dog with a jejunal blind loop. These workers also reported findings in agreement with data presented in the present study. In their dogs with blind pouches lipolysis was normal, hydroxy acid formation did not appear to be important, and bile salt metabolism appeared to be altered by bacteria proliferating in the jejunum. 
Further investigations are required since bacterial metabolites of bile salts are numerous and since the effects of such products on intestinal function are not known. Because of the limitations of the analytical techniques used, precise characterization of bile salt derivatives present in bacterially contaminated small bowel contents was not possible in this study. Furthermore, it remains to be demonstrated that the observed inhibition of in vitro uptake and esterification of fatty acid by rat intestine is meaningful in terms of fat absorption in the intact organism.

\section{Summary}

Steatorrhea that could be corrected by antibiotic therapy was investigated in one patient with the blind loop syndrome and in rats with surgically created blind pouches of small intestine.

After oral administration of either trioleincarboxylic- ${ }^{-14} \mathrm{C}$ or oleic acid- $1-{ }^{14} \mathrm{C}$ to rats with intestinal pouches increased quantities of radioactivity were recovered from the lipid fraction of feces. The percentage of radioactivity recovered correlated closely with the percentage of total fat intake that appeared in the stool.

No obvious histological abnormalities could be demonstrated by light microscopy in the jejunal mucosa of rats or the patient.

When ${ }^{14} \mathrm{C}$-labeled triolein was administered and intestinal contents analyzed for the radioactive lipids present, efficient intraluminal lipolysis of triolein was demonstrated in the patient as well as in rats at a time when steatorrhea was present. There was no significant uptake of labeled fats by bacteria proliferating within the intestinal lumen.

Uptake and esterification of oleic acid- $1-{ }^{14} \mathrm{C}$ by rat intestinal slices were inhibited by supernatant fluid obtained from bacterially contaminated intestinal contents. The inhibitory factor was heat stable, soluble in alcohol, and could be accounted for on the basis of the measured quantities of free deoxycholate present.

Incubation of cholic acid with mixed bacterial cultures obtained from blind pouches resulted in the production of a substance that was chromatographically similar to deoxycholate and that inhibited in vitro intestinal uptake and esterification of labeled oleic acid.
These observations suggest that malabsorption of dietary fat is the most likely explanation for steatorrhea in the blind loop syndrome. Defective absorption cannot be readily attributed to bacterial destruction of intestinal mucosa, to impaired lipolysis or triglyceride, or to bacterial uptake of ingested lipid. The results provide support for a possible role for bacterial alteration of bile salts.

\section{Acknowledgments}

I am grateful for the technical assistance of Miss Helen Corrigan and for the suggestions offered by Drs. Kurt Isselbacher and Robert Sheig.

\section{References}

1. Badenoch, J. The blind-loop syndrome in Modern Trends in Gastroenterology, F. A. Jones, Ed. New York, Hoeber, 1958, 2nd series, p. 231.

2. Doig, A., and R. H. Girdwood. The absorption of folic acid and labelled cyanocobalamin in intestinal malabsorption, with observations on the fæcal excretion of fat and nitrogen and the absorption of glucose and xylose. Quart. J. Med. 1960, 29, 333.

3. Donaldson, R. M., Jr. Malabsorption of $\mathrm{Co}^{80}$-labeled cyanocobalamin in rats with intestinal diverticula. I. Evaluation of possible mechanisms. Gastroenterology 1962, 43, 271.

4. Cooke, W. T., E. V. Cox, D. J. Fone, M. J. Meynell, and R. Gaddie. The clinical and metabolic significance of jejunal diverticula. Gut 1963, 4, 115.

5. Wirts, C. W., and F. Goldstein. Studies of mechanism of postgastrectomy steatorrhea. Ann. intern. Med. 1963, 58, 25.

6. Donaldson, R. M., Jr. Steatorrhea in rats with small bowel diverticula (abstract). Clin. Res. 1963, 11, 182.

7. Panish, J. F. Experimental blind-loop steatorrhea. Gastroenterology 1963, 45, 394.

8. Van de Kamer, J. H., H. T. B. Huinink, and H. A. Weyers. Rapid method for the determination of fat in feces. J. biol. Chem. 1949, 177, 347.

9. Jover, A., and R. S. Gordon, Jr. Procedure for quantitative analysis of feces with special reference to fecal fatty acids. J. Lab. clin. Med. 1962, $59,878$.

10. Cameron, D. G., G. M. Watson, and L. J. Witts. The experimental production of macrocytic anemia by operations on the intestinal tract. Blood 1949 , 4, 803.

11. Folch, J., M. Lees, and G. H. Sloane Stanley. A simple method for the isolation and purification of total lipides from animal tissues. J. biol. Chem. 1957, 226, 497.

12. Dawson, A. M., and K. J. Isselbacher. Studies on lipid metabolism in the small intestine with observa- 
tions on the role of bile salts. J. clin. Invest. 1960 , 39, 730.

13. Borgström, B., G. Lundh, and A. Hofmann. The site of absorption of conjugated bile salts in man. Gastroenterology 1963, 45, 229.

14. Sjövall, J. The determination of bile acids in bile and duodenal contents by quantitative paper chromatography. Clin. chim. Acta 1959, 4, 652.

15. Eneroth, P. Thin-layer chromatography of bile acids. J. Lipid Res. 1963, 4, 11.

16. Hofmann, A. F. Thin-layer adsorption chromatography of free and conjugated bile acids on silicic acid. J. Lipid Res. 1962, 3, 127.

17. Fisher, R. A. Statistical Methods for Research Workers, 11th ed. New York, Hafner, 1950, p. 122.

18. Webb, J. P. W., A. T. James, and T. D. Kellock. The influence of diet on quality of faecal fat in patients with and without steatorrhea. Gut 1963, 4, 37.

19. Asselineau, F., and E. Lederer. Chemistry and metabolism of bacterial lipides in Lipide Metabolism, K. Bloch, Ed. New York, Wiley, 1960, p. 337.

20. Schiffer, L. M., W. W. Faloon, R. B. Chodos, and E. L. Lozner. Malabsorption syndrome associated with intestinal diverticulosis: report of case with jejunal biopsy. Gastroenterology 1962, 42, 63.

21. Strauss, E. W., R. M. Donaldson, Jr., and F. H. Gardner. A relationship between intestinal bacteria and the absorption of vitamin $B_{13}$ in rats with diverticula of the small bowel. Lancet 1961, 2, 736.

22. Hofmann, A. F., and B. Borgström. The intraluminal phase of fat digest in man: the lipid content of the micellar and oil phases of intestinal content obtained during fat digestion and absorption. J. clin. Invest. 1964, 43, 247.

23. Saunders, D. R., and A. M. Dawson. The absorption of oleic acid in the bile fistula rat. Gut 1963, 4, 254.

24. Norman, A., and J. Sjövall. On the transformation and enterohepatic circulation of cholic acid in the rat. J. biol. Chem. 1958, 233, 872.

25. Portman, O. W., S. Shah, A. Antonis, and B. Jorgensen. Alteration of bile salts by bacteria. Proc. Soc. exp. Biol. (N. Y.) 1962, 109, 959.

26. Portman, O. W. Importance of diet, species, and intestinal flora in bile acid metabolism. Fed. Proc. 1962, 21, 896.

27. Kim, Y. S., N. Spritz, M. Blum, J. Terz, and P. Sherlock. Steatorrhea of blind loop syndrome: role of altered fatty acid and bile acid metabolism (abstract). Clin. Res. 1965, 13, 255. 